The following paper posted here is not the official IEEE published version. The final published version of this paper can be found in the Proceedings of the International Electric Machines and Drives Conference (2007 : Antalya, Turkey):pp.153-158

Copyright @ 2007 IEEE.

Personal use of this material is permitted. However, permission to reprint/republish this material for advertising or promotional purposes or for creating new collective works for resale or redistribution to servers or lists, or to reuse any copyrighted component of this work in other works must be obtained from the IEEE. 


\section{Analysis and Performance Evaluation of an Axial-Field Brushless PM Machine Utilising Soft Magnetic Composites}

\author{
Gene S. Liew, Nesimi Ertugrul and Wen L. Soong \\ School of Electrical \& Electronic Engineering \\ University of Adelaide, Adelaide, Australia \\ Email : gliew@eleceng.adelaide.edu.au
}

\begin{abstract}
One of the major research activities in electric machines involves the use of alternative magnetic materials. Soft magnetic composites (SMC) offer the advantages of 3D magnetic flux paths and low-cost manufacturing. This paper examines the analysis and modelling of a prototype axial-field permanent magnet machine which uses SMC. Measured parameters and performance with an inverter is compared to 3D finite-element simulations.
\end{abstract}

\section{INTRODUCTION}

The basic construction of electric motors using silicon iron (SI) laminations as the core material has not changed much for over a hundred years. However, recently soft magnetic composites (SMC), also known as powdered iron, has emerged as a promising alternative magnetic core material in electrical machine design, specifically for small and medium size machines [1-6]. SMC is produced by mixing fine iron powder with a plastic binder, and then compressing the mixture in a die to the final core shape under extremely high pressures [7-8].

SMC has two key advantages. Firstly, its isotropic nature and the moulding process readily allow the use of complex core shapes containing 3D magnetic flux paths. This extra degree of freedom, previously unavailable with the conventional laminated stator core construction, allows design topologies with innovative shape, reduced size and weight, and better copper utilisation. Secondly, the moulded construction gives the potential for low cost and high volume manufacturing.

One of the challenges with SMC is due to its higher iron losses. Iron losses in magnetic materials consist of two major components: eddy-current losses and hysteresis losses. Compared to conventional silicon-iron laminations, SMC has lower eddy-current losses, due to the iron particles being electrically isolated from one another by the binder, but has higher hysteresis losses, due to the large residual mechanical stresses in the iron particles produced by the moulding process. Overall, SMC has higher iron losses than SI at $50 / 60 \mathrm{~Hz}$ but the difference reduces as the frequency increases. This is because in SMC, hysteresis losses are dominant and these increase linearly with frequency, while in conventional laminations, eddy-current losses are dominant at higher frequencies, and these increase with the square of frequency. Typical iron loss characteristics for SMC and conventional laminations are shown in Fig. 1.

\author{
David B. Gehlert \\ Intelligent Electric Motor Solutions Pty. Ltd. \\ Adelaide, Australia \\ Email : davidg@diga.com.au
}

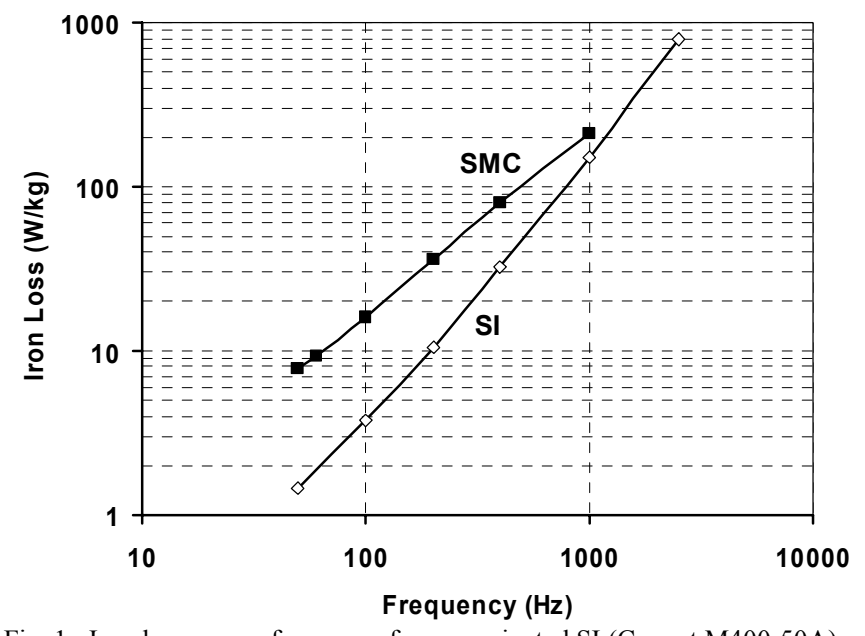

Fig. 1. Iron loss versus frequency for non-oriented SI (Cogent M400-50A) and SMC (Somaloy $550+0.6 \% \mathrm{LB} 1$ ) with a peak flux density of $1 \mathrm{~T}$.

SMC also has a relatively low relative permeability which means it is best suited to permanent magnet (PM) machines. Axial-field permanent magnet (AFPM) machine form a special class of PM machines. The 3D stator core geometries and flux paths available with SMC are very useful for AFPM. AFPM have been shown to be to achieve high torque and power densities, and higher efficiencies [9-11].

This paper investigates the modelling of the performance of a SMC-based AFPM prototype machine including comparison between the measured and simulated results based on 3D finite element analysis (FEA).

\section{PROTOTYPE SMC AFPM MOTOR}

Fig. 2 shows the prototype three-phase, four-pole SMC AFPM machine. This shows the stator core before after winding on the left, and the complete motor assembly on the right.

The stator core was made by precision machining from a cylindrical piece of SMC. It has twelve teeth, each wound with a concentrated winding. The stator coils were wound on a former and then slid into place allowing high copper packing factors to be obtained. Square cross-section copper wire was used in the prototype machine.

The rotor consists of four arc-shaped, surface-mounted magnet segments with a solid mild steel back-iron. The prototype machine used an unusually large airgap, $6.5 \mathrm{~mm}$ compared with the $2.5 \mathrm{~mm}$ magnet thickness. Possible reasons 
for this include : to reduce magnetic flux densities in the stator to avoid saturation or reduce stator iron losses; or to reduce the axial force on the machine to reduce bearing losses.

Table 1 summarizes some key parameters and dimensions of the prototype machine.

The choice of four poles in the prototype does not appear to be optimum as this low pole number can cause saturation in the stator back-iron.

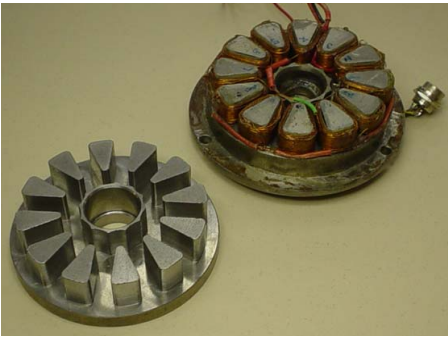

a

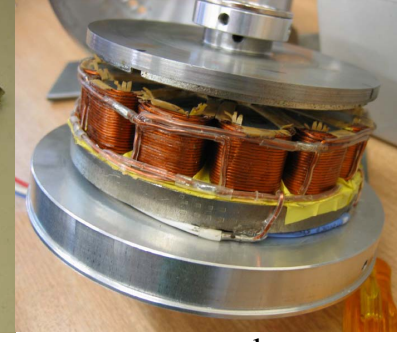

b
Fig. 2. The stator cores of the SMC based AFPM prototype motor, a) with and without coils, b) assembled stator and rotor

TABLE I

KEY PARAMETERS \& DIMENSIONS OF THE STATOR CORE

\begin{tabular}{|l|c|l|c|}
\hline Parameters & & Dimensions & $\mathrm{mm}$ \\
\hline Stator Core Material & Somaloy 550 & Outer Diameter & 110 \\
\hline Magnet Material & $\mathrm{NdFeB}$ & Inner Diameter & 30 \\
\hline Magnet Thickness & $2.5 \mathrm{~mm}$ & Base Height & 10 \\
\hline Number of Turns & 80 turns/tooth & Tooth Height & 20 \\
\hline Resistance (phase) & $0.75 \Omega$ & Shaft Diameter & 12 \\
\hline DC link voltage & $24 \mathrm{~V}$ & Air Gap Length & 6.5 \\
\hline
\end{tabular}

The AFPM motor was star-connected and driven by an inverter with a $24 \mathrm{~V}$ dc link voltage. The rotor position was obtained using three Hall-Effect sensors, which are excited by a separate PM disk attached to the end of the rotor. The test setup also includes a small dc machine, which was used to drive and load the AFPM motor for both parameter and performance measurements.

\section{3-D FINITE-ELEMENT MODELING}

Finite-element analysis (FEA) is a numerical method that can accurately analyze complex electromagnetic fields using Maxwell equations. Due to the 3D geometry of the axial-field PM machines, a 3D FEA package JMAG Studio $[12,13]$ is employed in this study to analyze, to simulate and to predict the characteristics of the motor under test.

The stator of the prototype AFPM machine has four poles and twelve stator teeth as shown in Fig. 2a. The structure of motor has a periodicity of 90 degrees. Hence, a quarter machine model is created to reduce the analysis computation time (see Fig. 3). The 3D model was first generated using the Solid Edge CAD software package and then imported into JMAG. The BH-curves and iron loss characteristics for different SMC material grades were already available in the JMAG material database. The simulation results are from a time-stepping, coupled-circuit 3D finite element simulation. The mesh of the model consists of 18,708 nodes and 62,360 elements. The execution of a single time step was approximately 15 minutes.
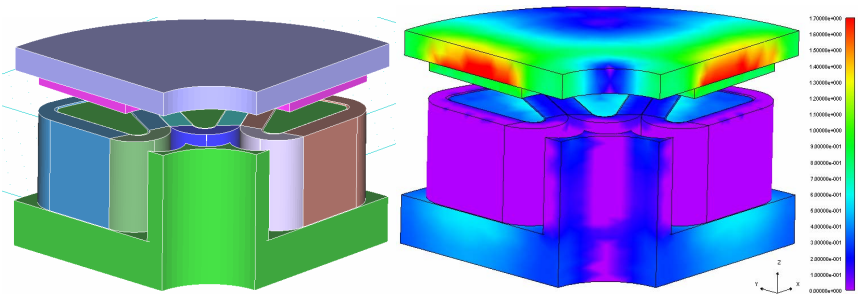

Fig. 3. 3D FEA quarter model of the AFPM motor configuration, solid model view (left) and contour view of magnetic flux density (right).

Fig. 3 shows the geometry of the machine model (left) and the contour plot of magnetic flux density (right). The analysis shows that the magnetic flux density on particular sections of the stator ranges from 0 to $2.3 \mathrm{~T}$.

\section{Performance Characteristic Studies}

The parameter and performance measurements on the AFPM test motor were conducted using the test setup described earlier. A similar experimental procedure to that described in [14] was performed. High bandwidth current and voltage transducers (Hameg HZ56 current probe, Yokogawa differential probe Model 700925) and a digital oscilloscope (Tektronix TDS 340A) were utilised to record the measurements.

\section{A. Back EMF and Tooth Flux}

The dc machine was used to drive the test motor and the open-circuit back EMF was recorded. Fig. 4 shows the simulated (from the 3D finite-element model) and the measured phase back EMF waveforms. There is a good correspondence between the two waveforms especially in the shape of the profile. This gives confidence in the accuracy of the 3D finite element approach used. The small discrepancies in their amplitudes may be due to dimensional errors or uncertainty in the exact remanent flux density of the magnets.

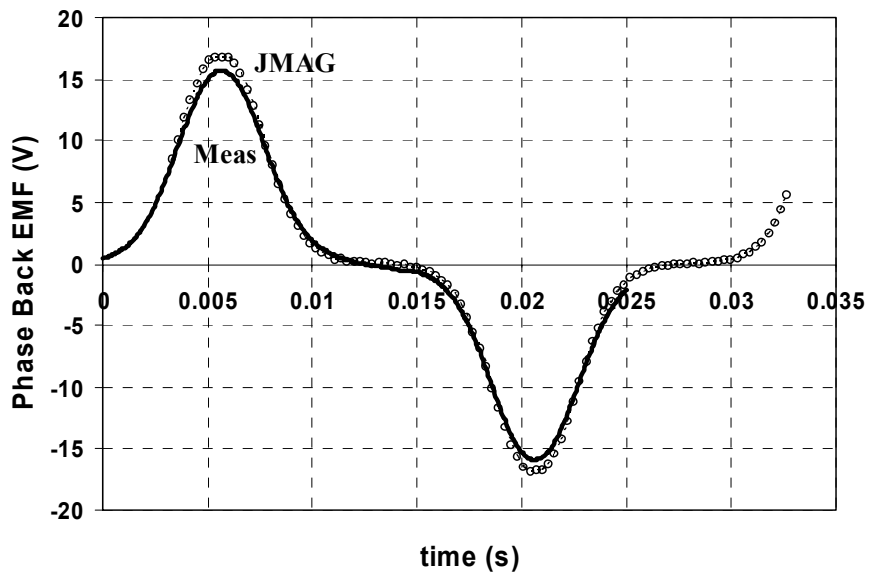

Fig. 4. Measured (Meas) and simulated (JMAG) phase back-EMF waveforms

Fig. 5 shows the simulated and measured magnetic flux density waveforms of a single tooth. The measurement was performed by placing a 10 turn search coil on the top section of the tooth. The induced voltage from the search coil was passed through an RC integrator to obtain the flux waveform and scaled to show flux density as shown in Fig. 5. Fig. 6 shows the 
magnetic flux density in the stator yoke. An experimental measurement of the yoke flux was not available as a search coil was unable to be inserted due to the design of the housing.

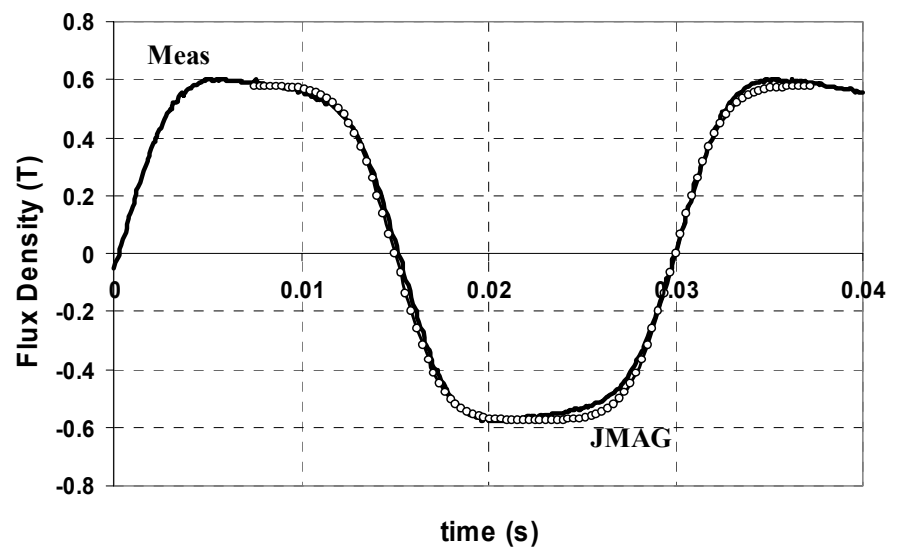

Fig. 5. Measured and simulated magnetic flux density waveforms in a stator tooth as a function of time.

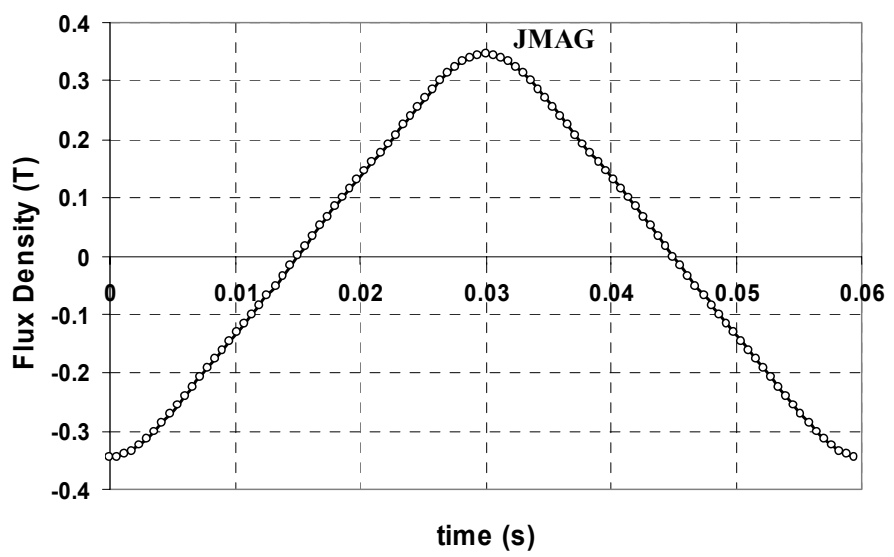

Fig. 6. Simulated magnetic flux density waveform in the yoke as a function of time.

\section{B. Cogging Torque and Axial Force}

The simulated plots for the axial force and the cogging torque under zero excitation are shown in Figs. 7 and 8. Fig. 7 shows that the single-sided configuration has a large average axial force of about $150 \mathrm{~N}$. This has the potential to produce large bearing losses that would affect the overall efficiency performance.

A simple measurement of the peak cogging torque was conducted using the dc machine as a torque transducer. The minimum dc machine armature current required to start it rotating was measured with dc machine both coupled to, and uncoupled from, the machine under test. The difference in armature current multiplied by the torque constant of the dc machine gives the peak cogging torque. A number of tests were conducted at different initial rotor positions and the measured upper and lower values are shown as horizontal lines in Fig. 8. It was observed that the measured peak values are comparable to the predicted values. The cogging torque can be reduced by utilising a double-sided stator design (a stator on each side of the disc rotor) configuration where the stators can be offset (skewed) with respect to one another.

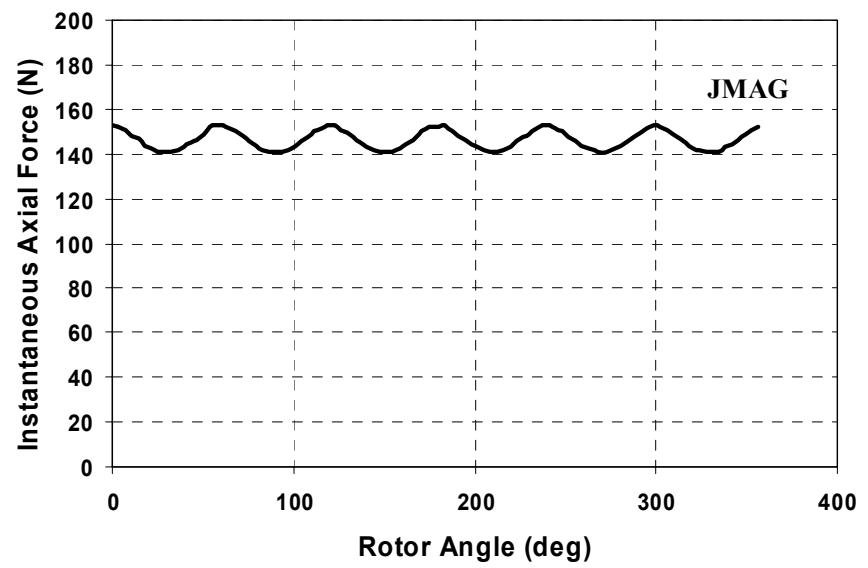

Fig. 7. Simulated axial force as a function of rotor angle

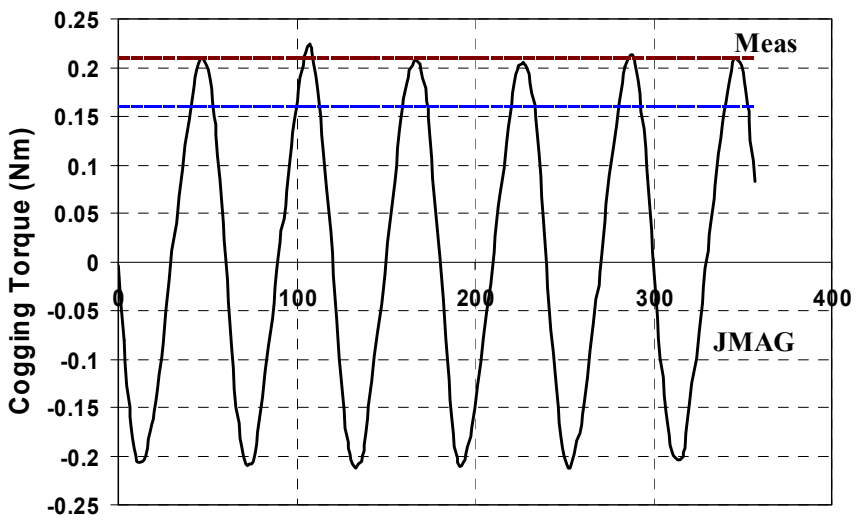

Rotor Angle (deg)

Fig. 8. Simulated cogging torque as a function of rotor angle, with the upper and lower range of measured values shown as horizontal lines.

\section{Iron loss and Inductance}

Fig. 9 shows the simulated iron loss and the measured open-circuit loss versus speed characteristic. The open-circuit loss was measured using the dc motor as a torque transducer. The test machine loss torque was estimated using the difference between the dc machine current as a function of speed, with it coupled, and not coupled to the test machine. The open-circuit loss measurement thus includes the test machine's windage and bearing losses.

In FEA, the iron loss was calculated using the available iron loss characteristics of the SMC material. A time-stepping FEA solution was performed and the flux density in each element in the model as a function of time was calculated. This was then used to calculate the iron loss in each element which was then integrated over the entire model volume to find the total iron loss. The calculated iron loss curve shown in Fig. 9 is the sum of both the hysteresis loss and eddy current loss components. The available iron loss curves have a range from 50 to $400 \mathrm{~Hz}$ and the data was extrapolated for frequencies outside of this range.

As can be seen from Fig. 9, the simulated values are much lower compared to the measured values. In addition, the simulated iron loss in under load is also higher compared to simulated open-circuit condition. 


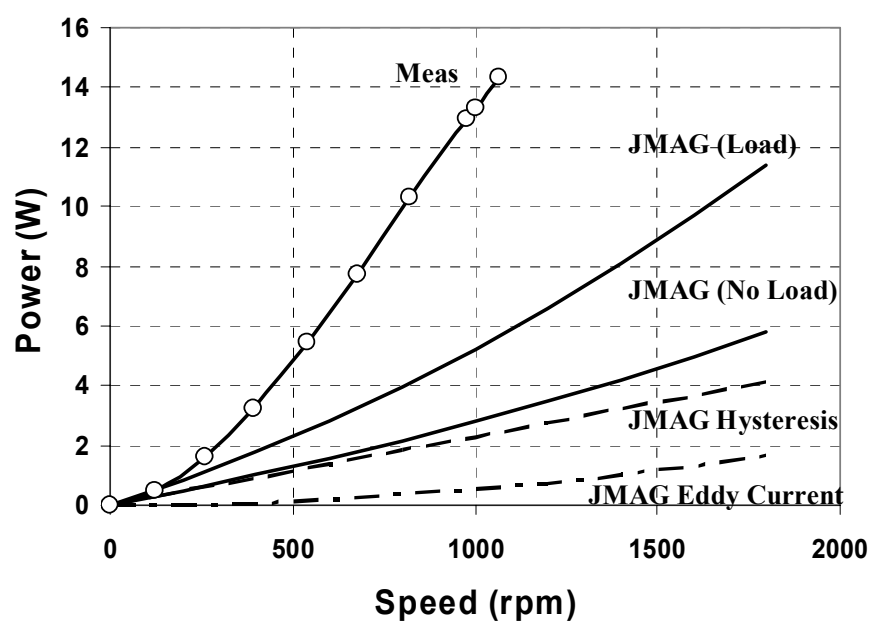

Fig. 9. Measured open-circuit loss and simulated iron loss curves.

To help understand the iron loss discrepancy, Fig. 10 shows the calculated iron loss if it is assumed the flux density in the stator is uniform throughout its volume, has no harmonics, and has a peak value of $0.5,1.0$ and $1.5 \mathrm{~T}$. The measured and calculated open-circuit curves from Fig. 9 are also shown for reference.

The simulated average magnetic flux density is $0.40 \mathrm{~T}$ which is closed to the measured average magnetic flux density of $0.35 \mathrm{~T}$ using the gauss meter. The simulated iron loss results are slightly higher than the losses for a uniform $0.5 \mathrm{~T}$ flux density in the stator, which is reasonable taking into account harmonics and rotational flux components. The higher measured values may be due to: poor magnetic loss characteristics of the particular SMC sample used; stray losses that were not considered in the simulation; and high bearing loss from the high axial force. Further investigation is required in this area.

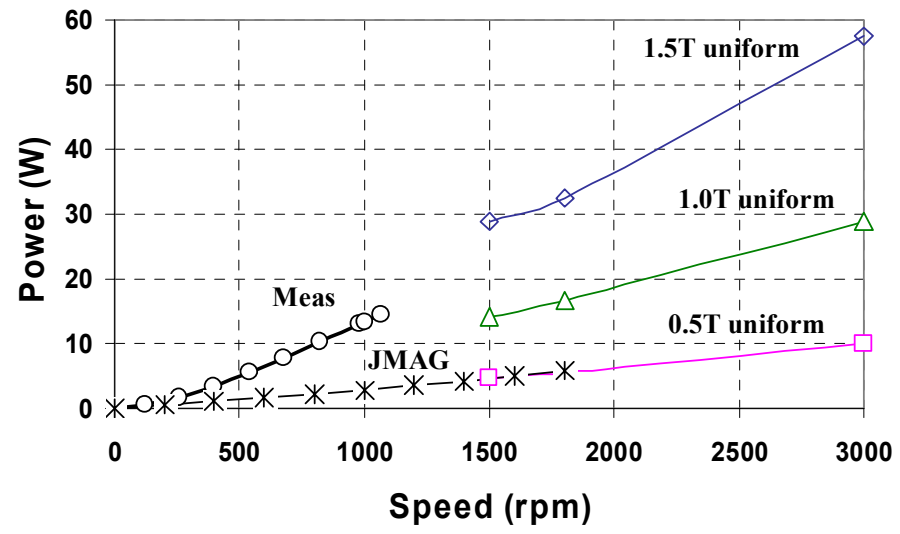

Fig. 10. Simulated iron loss versus speed curves assuming a uniform stator flux density of $0.5,1.0$ and $1.5 \mathrm{~T}$ peak. The measured and calculated open-circuit curves from Fig. 9 are also shown for reference.

The inductance of the test motor was measured using a standstill test by applying a single-phase $50 \mathrm{~Hz}$ sinusoidal voltage between phases $\mathrm{A}$ and $\mathrm{B}$ joined together, and phase $\mathrm{C}$. From the impedance and resistance measured, the reactance can be calculated and hence the inductance.

The inductance of the motor was calculated in FEA in both the $d$-axis (magnet axis) and the $q$-axis. Due to the large airgap, the calculated inductances in the two axes are very similar. Fig. 11 shows a comparison between the simulated and measured inductances. They show a reasonable correspondence with the measured values being about $30 \%$ smaller. The fact that the measured values are lower is somewhat unusual, at least based on 2-D finite-element experience with conventional radial flux machines.

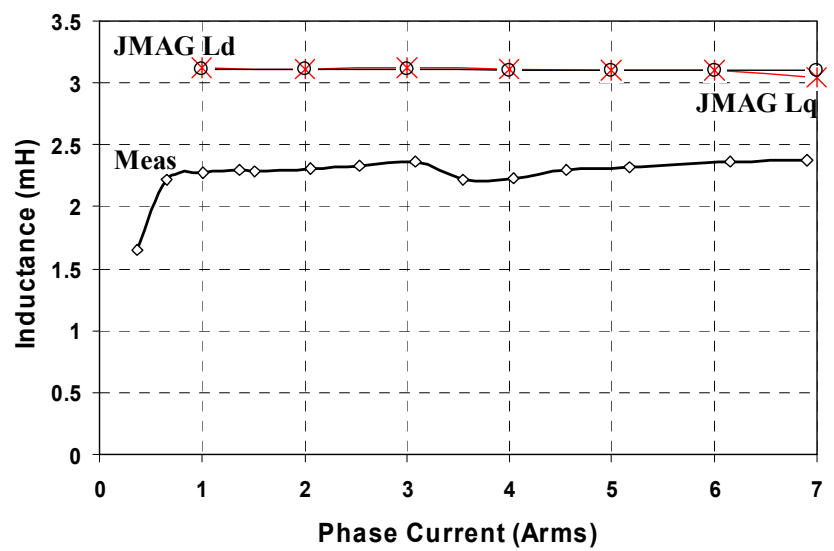

Fig. 11. Measured phase inductance, and simulated $d$-and $q$-axis inductance curves.

\section{Motoring Performance}

To calculate the machine performance with an inverter, a coupled-circuit, time-stepping 3D finite-element analysis run was performed. For 100 time-steps this simulation took approximately 25 hours. The circuit model used includes a six-step voltage-source inverter and the star-connected phase windings. The switching commutations were aligned with the back-emf waveforms. Fig. 12 gives the circuit diagram.
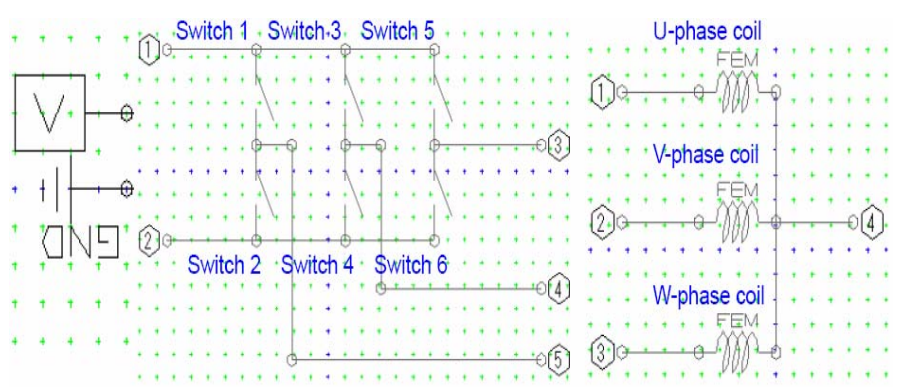

Fig. 12. Circuit diagram used in the time-stepping FEA program.

Figs. 13 and 14 show the measured and calculated line voltage and phase current waveforms. The simulation results are in reasonable agreement with the measured waveforms. The discrepancies in the waveforms are likely to be due to the error in the back-emf and inductance parameters. 


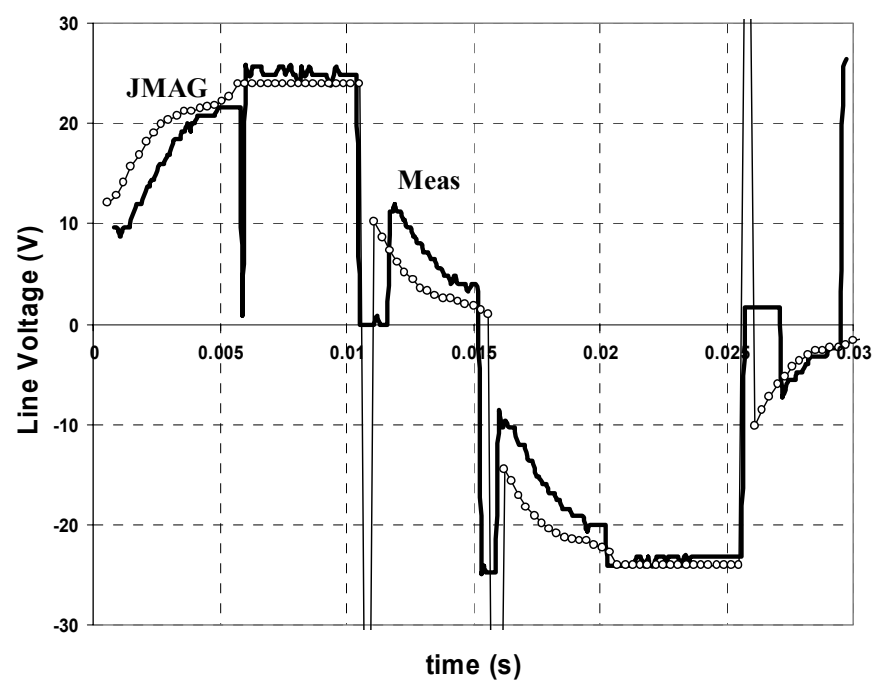

Fig. 13. Simulated and measured line voltage waveforms at $1000 \mathrm{rpm}$.

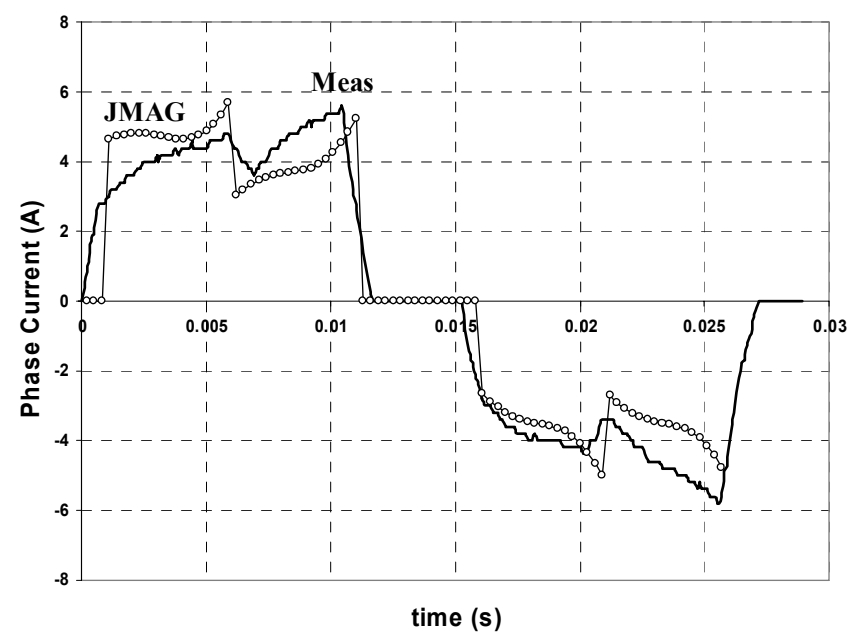

Fig. 14. Simulated and measured phase current waveforms at $1000 \mathrm{rpm}$.

\section{E. Load Performance and Efficiency}

The performance of the motor in six-step operation was examined. In the experimental test set-up the load on the test machine was varied by changing the resistive load on the dc machine. The coupled-circuit, time-stepping FEA model was used to simulate the performance. Fig. 15 shows a comparison of the measured and simulated output torque versus speed characteristics. Both characteristics show the expected linear drop in speed with increasing load. The higher output torque prediction is associated with the under-prediction of the open-circuit losses seen earlier.

Fig. 16 shows the measured and simulated efficiency as a function of load torque of the motor under test corresponding to the results shown in Fig. 15. The motor reached a maximum measured efficiency of $52 \%$ at a speed of $1000 \mathrm{rpm}$. The FEA calculated efficiency is significantly higher, again due to the under-prediction of the iron losses. In addition, the calculated efficiency shown in Fig. 18 is also included in the plot for comparison.

Fig. 17 shows the measured copper and iron loss breakdown of the test machine as a function of speed, corresponding to the results in Fig. 15. As the load increases and the speed drops, the lower fundamental frequency reduces the iron losses, but the increasing stator current produces large copper losses. It should be noted that the prototype machine used an unusually large airgap. If this airgap was reduced to a more conventional value this should significantly increase the back-emf and hence reduce the copper losses, but will result in an increased iron loss due to the higher flux densities.

Fig. 18 shows a contour plot of the calculated efficiency as a function of output torque and speed. This contour plot was based on the measured open-circuit loss characteristics and the measured back-emf and stator resistance. It assumes that the stator current is sinusoidal and in phase with the back-emf waveform at all times. In addition, the experimental results were also plotted as dot points in Fig. 18. The estimated efficiency characteristics are in good agreement with the measured results shown in Fig. 16.

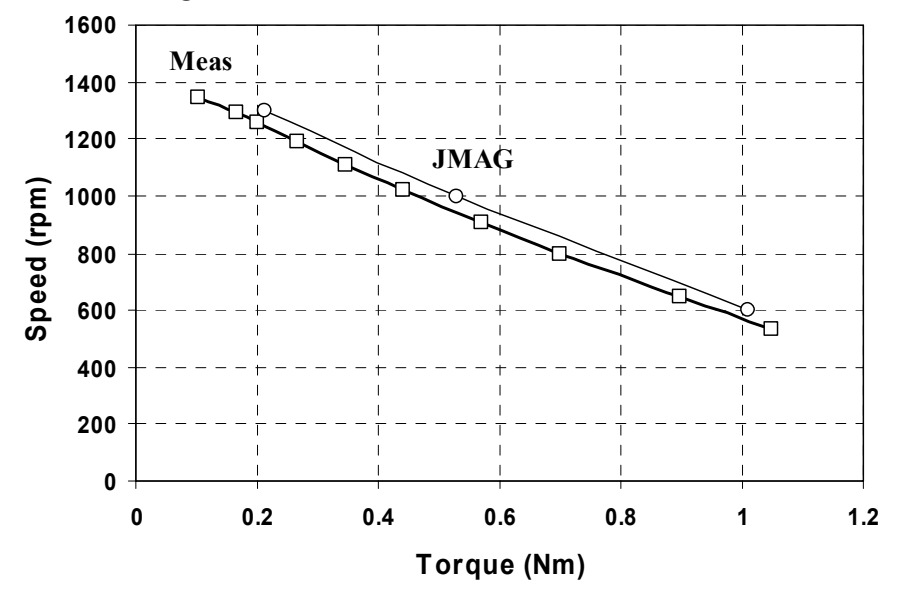

Fig. 15. Measured and simulated speed versus output torque.

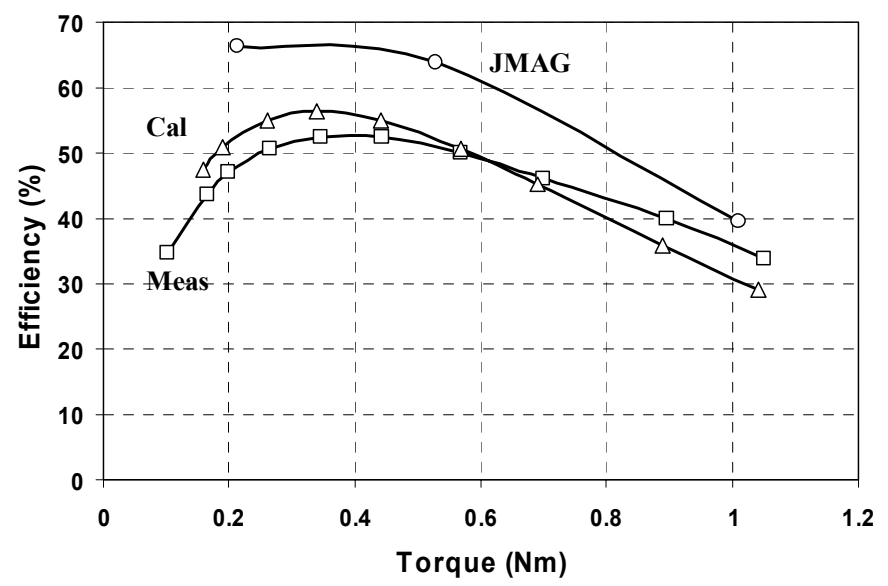

Fig. 16. Measured, simulated and calculated (Cal) efficiency versus output torque 


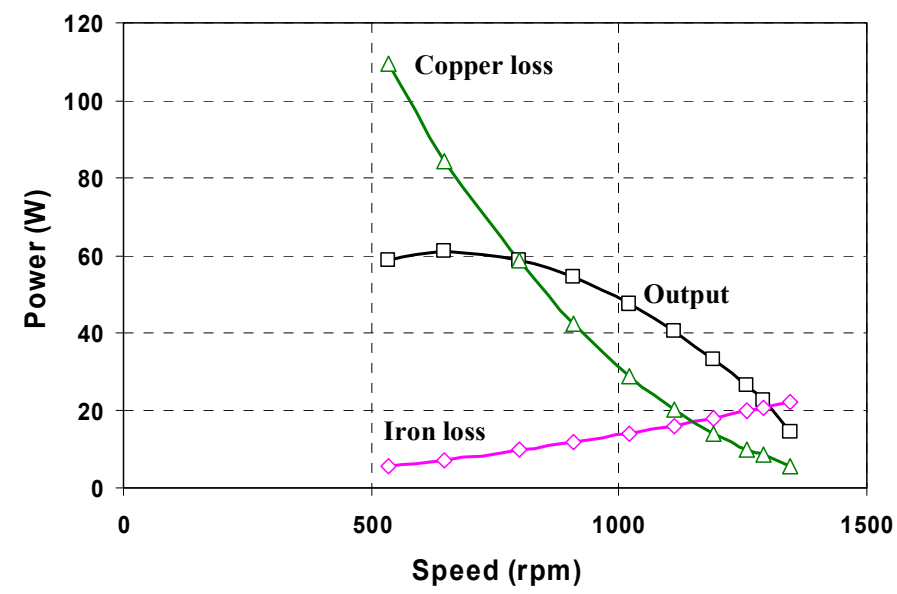

Fig. 17. Measured copper and iron loss breakdown versus speed corresponding to the results shown in Fig. 15. The measured output power is also shown.

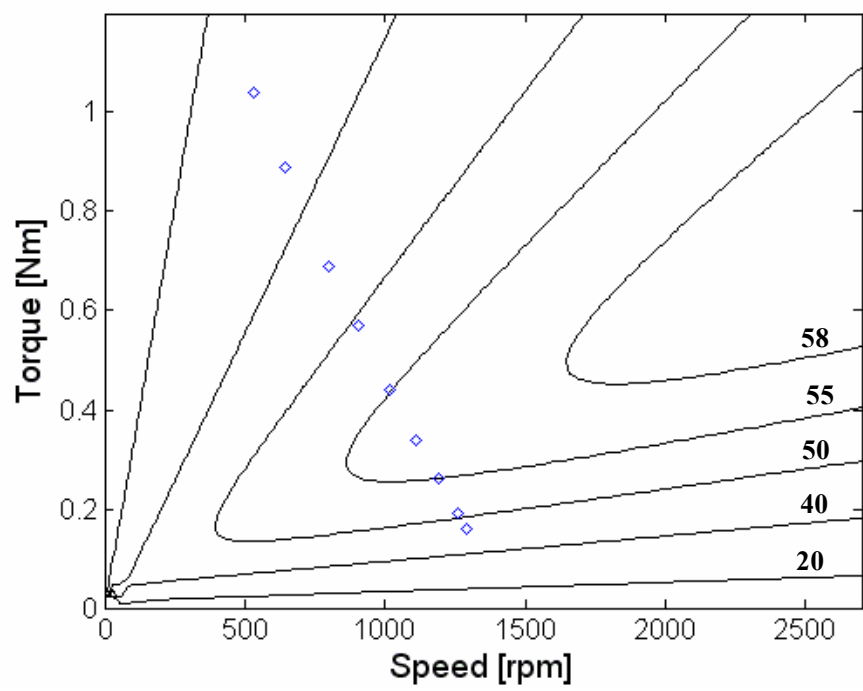

Fig. 18. Calculated efficiency contours and measured torque versus speed points (blue dot points)

\section{CONCLUSIONS}

This paper investigated the performance of a prototype axial-field permanent magnet (AFPM) motor utilising an emerging magnetic material, soft magnetic composite (SMC). The details of the comprehensive experimental and analysis results of the prototype SMC machine including description on the test rig and experimental procedures were presented in the paper. In addition, the paper also describes the details of the 3D finite element based design study and demonstrates its validity using comprehensive experimental results.

The motor parameters and its performance were measured and compared with the predictions from 3D finite-element analysis. The finite-element results show a good correspondence with the experimental results for the back-EMF profiles, cogging torque and torque versus speed characteristic, but further work is required on the iron loss and inductance prediction.

The prototype machine was an early design for which the emphasis was on concept demonstration. The validation of the use of 3D finite-element analysis to model this machine is the first step in optimising the machine geometry to improve its performance. It is planned to investigate the effects of design changes such as reducing the airgap and increasing the number of poles. After appropriate optimisation, it is expected that AFPM SMC machines would be able to offer efficiencies which are comparable with conventional machines, particularly at higher speeds. This would make AFPM SMC machines attractive for high volume, low-cost applications.

\section{ACKNOWLEDGMENT}

The authors would like to thank the Australian Research Council (ARC Linkage Project: LP0455574) for supporting this project and the staff of the School of Electrical and Electronic Engineering's mechanical workshop for their help with the experimental testing.

\section{REFERENCES}

[1] L. Pennander, G. Nord, K. Maezawa, M. Saito and D. Derchowitz, "Design of Soft Magnetic Composite Components for Tubular Linear Motors", paper presented at Motor and Drive Systems Conference, Miami, Florida, US February 2006.

[2] M. Persson, G. Nord, L. Pennander, G. Atkinson and A.G. Jack, "Development of Somaloy Components for a BLDC motor in a Scroll Compressor Application", paper presented at Powder Metallurgy (PM) World Congress \& Exhibition 2006, Busan, Korea September 2006.

[3] L. Hultman and A.G. Jack, "Soft Magnetic Composites - Motor Design Issues and Applications", paper presented at Powder Metallurgy and Particulate Materials (PM2TEC) 2004, Chicago, USA June 2004.

[4] L. Hultman, M. Persson and P. Engdahl, "Soft Magnetic Composites for Advanced Machine Design", paper presented at Powder Metallurgy Asia 2005, Shanghai, China April 2005.

[5] L. Hultman, "Existing and Future Automotive Applications for Soft Magnetic Composites", paper presented at Powder Metallurgy (PM) 2004, Vienna, Austria October 2004.

[6] Y. Enomotor, et al., "Evaluation of Experimental Permanent-Magnet Brushlesss Motor Utilising New Magnetic Material for Stator Core Teeth", IEEE Transactions on Magnetics, Vol. 41, No. 11, pp. 4304-4308, November 2005.

[7] L. Pennander and A.G. Jack, "Soft Magnetic Iron Powder Materials AC Properties and their Application in Electrical Machines", paper presented at EURO Powder Metallurgy (EURO PM) 2003, Valencia, Spain October 2003.

[8] L. Hultman and Z. Ye, "Soft Magnetic Composites - Properties and Applications", paper presented at Powder Metallurgy and Particulate Materials (PM2TEC) 2002, Orlando, USA June 2002.

[9] A.H. Wijenayake, J.M. Bailey and P.J. McCleer, "Design Optimisation of an Axial Gap Permanent Magnet Brushless DC Motor for Electric Vehicle Applications", IEEE Industry Applications Conference 1995 Thirtieth IAS Annual Meeting, Orlando, FL, USA, 1995.

[10] F. Profumo, Z. Zhang and A. Tenconi, "Axial Flux machines Drives: A new Viable Solution for Electric Cars", IEEE Transactions on Industrial Electronics, Vol. 44, No. 1, pp. 39-45, February 1997.

[11] Press Releases, Light Engineering Inc, USA. Available: http://www.lightengineering.com/news.htm

[12] JMAG-Studio 8.3 User's Manual Pre/Post (English version), JMAG-Studio Group, Engineering Technology Division, The Japan Research Institute, Ltd., Tokyo, Japan, 2005.

[13] Analysis of Axial Gap Motor Using "Patch Mesh" Function, JMAG-Studio Group, Engineering Technology Division, The Japan Research Institute, Ltd., Tokyo, Japan, 2005.

[14] G.S. Liew, N. Ertugrul, W.L. Soong and J. Gayler, "Investigation of Axial Field Permanent Magnet Motor Utilising Amorphous Magnetic Material", Australasian Universities Power Engineering Conference (AUPEC) Proceedings, Vol. 2, pp. 592-597, Hobart, Australia, September 2005. 